\title{
Substantial reduction in child stunting is differentially associated to geographical and socioeconomic disparities in Misiones Province, Argentina
}

Pablo A. Nuñez ${ }^{1,2}$, María Soledad Fernández ${ }^{1}$, Pablo Turjanski ${ }^{3}$, Adriana Pérez ${ }^{1}$, María Romina Rivero², Carlos De Angelo ${ }^{4}$, Oscar D. Salomón², Gerardo Cueto ${ }^{1}$

${ }^{1}$ Grupo de Bioestadística Aplicada, Universidad de Buenos Aires, Argentina

${ }^{2}$ Instituto Nacional de Medicina Tropical, Puerto Iguazú, Argentina

${ }^{3}$ Departamento de Computación, Consejo Nacional de Investigaciones Científicas y Técnicas, Buenos Aires, Argentina

${ }^{4}$ Instituto de Ciencias de la Tierra, Biodiversidad y Ambiente, Río Cuarto, Argentina

\section{Abstract}

Objective: To estimate trends in the prevalence of child stunting in the population of children under 5 years of age covered by public health programs, between 2009 and 2014 in Misiones, Argentina.

Methods: Using Bayesian model-based geostatistics, we evaluated 724,872 anthropometric measurements corresponding to 110,633 children. In order to identify disparities at local scale we evaluated the hypotheses of a differential reduction of stunting according to the geographical location (at two-level spatial resolution) and to the socioeconomic level in a rural or urban environment.

Results: The prevalence of stunting had fallen significantly in the province overall. Sex and age defined gender disparities at individual level, and there were regional disparities with higher prevalence values in the north and northeast regions. In these areas stunting decreased to a greater degree during the studied period, although the spatial pattern remained smoother. Stunting increased in peripheral urban and dispersed rural areas that are socioeconomically vulnerable.

Conclusions. The spatial multi-level geostatistical estimates of child undernutrition provide a precision public health tool to target public policies to those populations with the greatest need, in order to reduce health disparities.

Keywords: child; stunting; inequalities; INLA; Argentina

\section{Introduction}

Socioeconomic and environmental vulnerability lead to inequalities that compromise children's potential growth and development, and increase child morbidity and mortality (1-3). Children's health, in particular

This article has been accepted for publication and undergone full peer review but has not been through the copyediting, typesetting, pagination and proofreading process, which may lead to differences between this version and the Version of Record. Please cite this article as doi: $\underline{10.1111 / \text { TMI.13400 }}$

This article is protected by copyright. All rights reserved 
malnutrition levels, is affected by several socioeconomic and environmental factors, such as household conditions, food insecurity, disease burden, and poverty, thus reflecting the level of social and economic development in a given territory (4).

Inequalities at early ages are mainly expressed as child undernutrition which comprises a subset of indicators determined by the relationship between insufficient height or weight with age. Stunting is the most prevalent form of undernutrition and is considered the best indicator of inequalities in children's health since it reflects a cumulative deficit in linear growth during the prenatal period and the first years of life (5). Not only does it affect children's physical, cognitive, social and emotional development, but it also generates adverse consequences in the educational and economic development during their adult life (6-8).

During the past decade, a combination of innovative health programs, such as Plan Nacer (20042013) and Programa Sumar (2013-) (9, 10) with conditional cash transfer programs (Asignación Universal por Hijo (AUH)), have been implemented in Argentina with the aims of reducing inequalities in access to health and improving living conditions, with focus on the most vulnerable populations. These health programs introduced changes in the framework of incentives to Public Health Care Centres (PHCC) to increase equitably the access and quality of prioritized health services. Both strategies, synergistically implemented, promoted health checks as a requirement to improve the developmental conditions of vulnerable families as well as preventive health care, nutrition, and education. Moreover, the programs centralize a large volume of high-quality subnational information with a broad coverage and representativeness of the target population (11).

Robust subnational primary information resulted in precise models of spatial-temporal disease maps that are essential tools to evaluate advances or areas demanding improvements. Although the countrylevel estimates are essential for global comparisons, they mask disparities at subnational levels at which most health or nutrition policies are implemented. Precision public health combining modelled geospatial and temporal resolved data is increasingly being used to direct more efficient interventions to more vulnerable populations (12-14).

We have previously described national and regional trends in undernutrition (stunting and underweight) among 1.4 million children under five (13 million records) covered by the above-mentioned programs in 6,386 PHCC with broad coverage of vulnerable populations in Argentina (11). We found that the prevalence of stunting decreased by $45.0 \%$ (from $20.6 \%$ to $11.3 \%$ ) and that of underweight by $38.0 \%$ (from $4.0 \%$ to 2.5 ) with differences between rural and urban areas, sex, age, regions and seasons (11).

In this work we applied Bayesian model-based geostatistics to estimate trends and to map the prevalence of stunting in children under 5 years of age with coverage of public health programs in 
Misiones province from 2009 to 2014. In order to identify regional disparities and persistent spatial patches, we evaluated different subnational levels (province, departments and health centre area). We modelled stunting at two-level spatial resolution (department-level and health centre influence arealevel) and evaluated two specific hypotheses: (i) the reduction of stunting differs with geographical location (space-time interaction) and (ii) the reduction of stunting differs according to socioeconomic level.
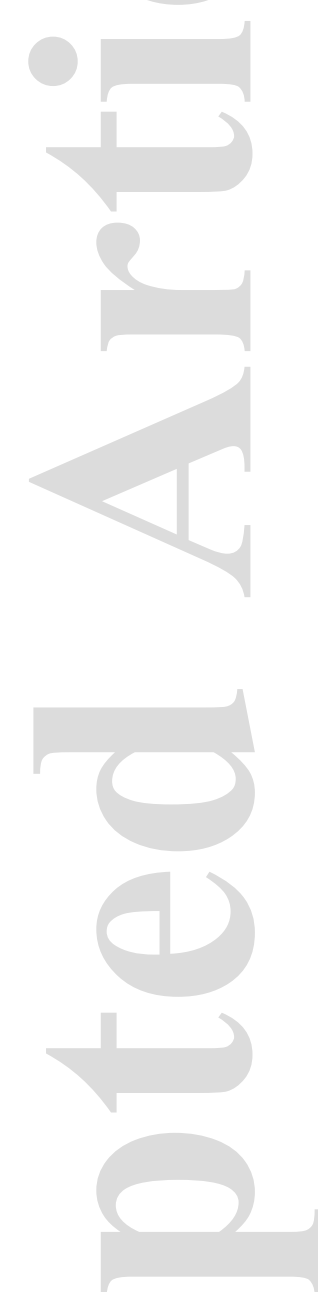

This article is protected by copyright. All rights reserved 


\section{Methods}

\section{Study area}

Misiones, a subtropical province in the northeast of Argentina (Figure 1A), is part of the most biodiverse ecoregion in the country, the Upper Parana Atlantic Forest, that is characterized by a subtropical climate with no dry season (15). The province level is the first administrative subnational level in Argentina. The province is divided into 17 departments and includes three main big cities where $46.3 \%$ of the total population live: Posadas (29.5\%), Oberá (9.8\%) and Eldorado (7.1\%). The province includes urban, periurban, rural areas, Mbyá Guaraní indigenous villages, and a large area covered by native forests. A total of 288 geolocated PHCC were analyzed as the lowest geographical level (Figure 1B).

\section{Data source}

Approximately one million anthropometric measurements were collected as a robust primary data source according to Plan Nacer and Programa Sumar program operations during the evaluated period (2009 to 2014). In the first wave of data clean-up, approximately $20 \%$ of the total records were removed for further analysis (Text S1). Thus 724,872 individual anthropometric measurements corresponding to 110,633 unique individuals were evaluated in 288 geolocated PHCC with a broad coverage of the most vulnerable target population (Figure 1, Figure S1). On the basis of the available individual-level data for each health check up (age, sex and height) and age- and sex-specific growth standards, $z$ scores were calculated for each measure using the LMS method $(16,17)$. Stunting was defined as $z$ scores two or more standard deviations (-2 SD) below the reference median for height-for-age (HAZ). For the condition not stunted/stunted the Bernoulli variable $(0,1)$ was assigned, respectively. The prevalence of stunting was defined as the proportion of children who fall below -2 SD.

\section{Socioeconomic and environmental conditions}

Each PHCC was classified in a stratified way according to their rural or urban context and their high or low socioeconomic level. First, the spatial influence area for each PHCC was defined using the well-established method of Voronoi tessellation in the Euclidean coordinates (18). For this, given a pair of XY spatial coordinates from each PHCC ( $n=288)$, a polygon area was defined as a partition of the space that describes the closest area to this geocoded point (Figure 1B). Second, each Voronoi polygon was classified as rural or urban according to the percentage of rural or urban households recorded in the last national census in 2010 (19). Third, inside each stratum (rural or urban), each polygon was classified as high or low socioeconomic level. For this, the k-means clustering method was applied to 13 socioeconomic variables (19) (Table 1). Thus, according to the described method, each PHCC was assigned to one of the clusters 
defined: urban context with high socioeconomic level (urban-high), urban context with low socioeconomic level (urban-low), rural context with high socioeconomic level (rural-high) or rural context with low socioeconomic level (rural-low).

\section{Statistical analysis}

In order to estimate trends in prevalence of stunting and spatial-temporal relative risk maps at different geographic levels during the evaluated period (2009 to 2014), different models were fitted using Bayesian space model-based geostatistics, using Integrated Nested Laplace Approximations (INLA) bundled in the R-INLA library (20-22).

Individual-level models: In this first model the whole dataset (individual-level data) and covariates were used to fit the model parameters and predict the prevalence of stunting from 2009 to 2014 . The annual trends in prevalence of stunting in the whole province (by sex) and the prevalence of stunting with age (by sex) were evaluated. The model included date (month and year of the health check up), age (in days) and sex as fixed effects. The anonymous individual identification was incorporated in the model as a random effect to control repeated measures. For continuous variables (year and age) a nonlinear smoothed effect was applied by using the random walk 2 method (21). Not stunted/stunted individual data (Bernoulli distribution) were modelled within a Bayesian hierarchical modelling framework using a Gaussian distribution to fit prevalence. Due to the amount of data (over 700,000 million records and 110,000 levels for random effects according to each individual), this estimation procedure guarantees the convergence of the estimates to the true parameter values (prevalence values) under the stated model (11).

Spatio-temporal models: The relative risk $\left(r_{i j}\right)$ of stunting was estimated in two different models, one for each spatial aggregation level. One for the $i$-th department-level $(n=17)$ and the other for the $i$-th PHCC-level ( $n=288$ ), for each different $j$-th year during the evaluated period (2009 to 2014) within a Bayesian modelling framework using a Poisson distribution. The number of stunted children acts as the response variable and the number of expected cases $(E)$ as an offset (21). In order to display the estimated posterior mean values of the relative risk of stunting for each area and year, the first year (2009) was chosen as the basal risk. First, we calculated the reference rates as the prevalence of stunting in 2009 in all possible combinations between age (0, 1, 2, 3 and 4 years) and sex groups (male and female). We computed the cumulative expected cases per area and year (Eij) as the product of the reference rates and the population at risk by age-groups and sex. To allow for an interaction between space and time (differences in the time trend in relative risk of stunting for different areas) we fitted different models including two-unstructured effect (Type I), temporal (Type II), spatial (Type III), and 
spatio-temporal (Type IV) structure (23). The Type I model was selected considering it was the best in terms of a trade-off between model fit and complexity (smallest DIC value). This procedure is an indirect method to compare stunting cases in areas and times, controlling for different population structures of child age and sex, using as the reference condition the whole province at the first year of the evaluated period. The estimated prevalence for each area and time was obtained as the product of the $r_{i j}$ predicted by the model with the observed prevalence of the whole province at the first year. We assumed a Gaussian exchangeable prior to model unstructured spatial and temporal effects, a RW2 prior for the structured temporal component and an intrinsic conditional autoregressive prior (iCAR) for the spatially structured variability (21). We considered log Gamma (1, 0.0005), the default specification of R-INLA, for the prior distribution of the hyperparameters. Previously, a sensitivity analysis was performed to assess the impact of different hyperprior choices. Since the estimates were quite similar in the different scenarios, we only showed the estimates obtained using the default specification.

The prevalence of stunting per socioeconomic an environmental conditions cluster (rural-high, rurallow, urban-high or urban-low) was estimated using a third model. We use the same approach as described above where the relative risk $\left(r_{i j}\right)$ of stunting was estimated by cluster, including an interaction between cluster and year as a random effect. First, we generated four dummy variables crossing the socioeconomic level (low/high) with urbanization level (rural/urban). Then, we included each dummy variable with the time variable (year) in an interaction term using model random walk 2.

For each PHCC influence area, the annualized decrease $(A D)$ was estimated as the slope of the linear regression for the predicted prevalence of stunting regressed by year.

\section{Ethics statement}

Ethical approval was obtained from the Bioethical Committee Comité de Ética en Investigación Provincial (CEIP) of Posadas city int Misiones province, Argentina. We specially attended to the regulations concerning personal data protection of national law No. 25.326/2000 and the principles expressed in the Declaration of Helsinki.

\section{Results}

We analyzed a total of 724,872 individual anthropometric measurements corresponding to 110,633 children under 5 years (male 50.2\%; female 49.8\%) recorded from 2009 to 2014. The analyzed child population from 2010, the year of the last national census, represented $38.4 \%$ of all children under 5 years in the province $(43,329 / 112,934)$. The number of children under 5 years evaluated remained relatively constant, around 40,000 per year (Figure S1). Thus, we analyzed a large volume of high-quality 
information with a broad coverage of the more vulnerable target population. Age-specific rates by sex are shown in Figure S1.

According to the individual-level model, the global prevalence of stunting for children under 5 years in the province overall decreased from $16.2 \%$ in 2009 to $9.4 \%$ in 2014, representing a relative decrease of $41.8 \%$ (Figure $2 \mathrm{~A}$ ). We found that stunting was more common in males than in females with a persistent difference (Figure 2B).

According to the trends in prevalence of stunting with age, we found higher values for both males and females around the neonatal period which declined during the next nine months, followed by a pronounced increase between nine and 18 months, after which we observed a continuous decreasing trend with age. These results exhibited significant differences by sex mainly during the first two years of age, including a mild displacement of the peak (Figure 3).

We observed a clear seasonality effect in the magnitude of child stunting prevalence with a peak during the months of the cold season, from June to August (Figure S2).

The application of spatio-temporal models to different spatial scales allows to describe the spatial effects that characterize the association of specific geographical factors of each area and level (department and health center) with the prevalence of stunting. The spatial effect (that only includes the spatial component) can be interpreted through the spatial patterns that show the contribution of each area to the increase/decrease of the prevalence of stunting. We identified a clear spatially structured pattern at department-level with higher prevalences and relative risk in the north and northeast regions (Figure 4A, Figure S3A). The estimated prevalence values per department ranged between $12.7 \%$ and 20.9\%. At health center-level we observed a similar but more heterogeneous pattern with higher prevalences and relative risk in the north and northeast regions (Figure 4B, Figure S3B). The estimated prevalence values ranged between $6 \%$ and $47.5 \%$. The median value of the estimated prevalence of stunting was $15.3 \%$. A total of 75 health centres (26\%) showed prevalence values higher than $20 \%$.

The spatio-temporal model applied includes an interaction between space and time in order to evaluate the hypothesis of a differential reduction of stunting according to the geographical location. The analysis at departmental level (Figure 5) showed that in the initial years of the studied period, prevalence values in the departments of the northern $(>15 \%)$ and northeastern regions $(>20 \%)$ were high but dropped substantially over the study period. Although the spatial pattern at the department-level remained, it was smoother (less than 15\%) and more homogeneous in all but one department which showed a persistently high prevalence (Figure 5, Figure S4A, Figure S5). Regarding the socioeconomic indicators, we found that the highest prevalence values corresponded to departments with low socioeconomic indicators located in the east (rural) and west (urban) regions (Figure S4B).

This article is protected by copyright. All rights reserved 
The analysis at the health centre level (Figure 6) showed the same spatial structure as at departmental level, with higher prevalence values in the north and northeast regions. In the initial years of the studied period, some areas had very high prevalence that were greater than $30 \%$ or $40 \%$. We observed a decrease of stunting prevalence and relative risk in most health centers achieving a more homogeneous situation. Despite the decrease, the spatial pattern and the persistently high prevalence areas remained in some patches distributed throughout the province (Figure 6, Figure S6).

To achieve a deeper understanding of the causes of the dynamics over time and the description of persistent patches, we evaluated the hypothesis that the reduction of stunting differs according to socioeconomic level and environmental conditions. A similar number of the PHCC corresponded to rural and urban areas (145 and 141, respectively). About $37 \%$ of the PHCC were assigned to a rural/low socioeconomic cluster, with a wide distribution along the province, mostly located in the northeast region and throughout the east margin. Only $13 \%$ of the PHCC corresponded to rural/high socioeconomic condition and showed a dispersed distribution. Urban PHCC were equally distributed according their socioeconomic level (25\%). More consolidated urban areas showed higher levels of socioeconomic conditions, whereas periurban areas showed lower levels of socioeconomic conditions (Figure 7A, Table 1).

We evaluated the annual trends in the prevalence of stunting of the four groups and found a significant interaction between socioeconomic level and decrease of stunting (Figure 7B). The urban/low socioeconomic condition cluster showed higher values during all years, but a higher relative decrease. The rural/low socioeconomic cluster showed a similar trend with lower values. Rural/high and urban-high socioeconomic condition clusters showed moderately decreasing trends and lower stunting prevalence. Overall, we found significant differences between clusters at the starting points but a significant closing gap between them over the years, reducing disparities across the province. The three main cities Posadas, Oberá and El Dorado showed a clear low-high socioeconomic pattern (north-south or east-west) which was differentially associated with higher prevalences (Figure 7C, Figure S7).

\section{Discussion}

In this work, we describe a substantial relative decrease of $41.8 \%$ in the prevalence of stunting among children under 5 years of age covered by the public health programs Plan Nacer and Programa Sumar in Misiones province between 2009 and 2014. The analyzed population corresponded to $38.4 \%$ of all children under 5 years of age in Misiones, providing a broad coverage of the more vulnerable population of the province. Our results are representative for the target population of children that is substantially more vulnerable to undernutrition than the child population overall.

This article is protected by copyright. All rights reserved 
Our findings showed that stunting prevalence was higher in males than in females during the six-year period analyzed, consistent with previous work which describes a persistent difference with sex (11). Moreover, the prevalence of stunting varied with age. Higher prevalences in males tend to dissipate by the age of 36 months. This sex difference has been previously reported for several countries, but is not often presented as a global pattern (24-26). This finding may indicate that males tend to be born smaller than females or that they are differently affected by sociocultural habits during the first years of life (27).

Seasonality shapes temporal growth patterns. This interaction must gain importance with climate change because of the impact of extreme events, heat and cold waves, droughts, rainfall variability, food availabilities and infectious disease burdens, among other environmental determinants that affect undernutrition (28-30).

Taken together, child's sex and age plus seasonality are relevant factors to be taken into account for designing specific public policies to reduce the prevalence of malnutrition.

This is the first report where models with two-level of spatially structured effects have been used to estimate stunting prevalence of Argentina. The inclusion of two spatial levels of analysis allows to disaggregate particular cases that might be masked by a higher level of aggregation. This means that a department which is not a high-risk area may harbor some health centers with a significantly higher spatial effect than neighboring areas. This is particularly important for targeted interventions in specific territories.

Both proposed hypotheses were successfully evaluated in this work. Regarding the first hypothesis, the departments presented different initial values, with a clear spatial pattern and higher prevalences in the northern and northeastern regions. Some areas showed a greater decrease during the evaluated years, although their spatial structure remained smoother. This was observed at the two spatial levels analyzed in this study.

To test the second hypothesis, we conducted a clustering analysis to group the health centre areas according to their socioeconomic level and their rural or urban context. It is important to note that in Misiones province, as in other regions of developing countries, most people live in urban areas although a vast proportion of the territory are rural (31). With this approach we shaped four clusters that showed a good separation according to the selected socioeconomic variables.

We identified different contexts characterized by higher prevalence of stunting. The first is urban areas with lower socioeconomic indicators that concentrate the largest population. They have higher levels of unemployment and overcrowding at home, and low indicators of development and access to public services. These areas are characterized by rapid and unplanned growth and urbanization and showed a north-south or east-west pattern, or they are located in the peripheries as a product of an 
unplanned growth of the cities. The second is rural areas with lower socioeconomic indicators that occupy the greatest extension in the province and have extremely poor infrastructure and access and quality of public services. Also, they are usually inhabited by indigenous populations that have indicators of malnutrition that double or triple the general population indicators (32). Therefore, we consider that public policies to reduce levels of stunting should be designed through two different strategies, one for the urban context and one for the rural context.

We found a substantial reduction in health inequalities, thus narrowing stunting gaps between clusters that were evidenced by the different initial and final values. Deeply rooted in poverty, stunting is a phenomenon influenced by a wide range of social health determinants $(1,8)$. The assignment of the rural or urban category together with socioeconomic variables allowed us to characterize the impact of the poverty environment. Moreover, the applied models to estimate stunting match the expected results according to the level of development of the cluster areas, which validates the approach. Strengthening national health inequality monitoring systems is an essential strategy to reduce social inequalities among different population groups and ensure that public policies are equity-oriented and effective $(33,34)$.

Precision public health strategies based on the use of robust primary data and the application of spatio-temporal statistical analysis are increasingly recognized by the global research and political health community (35). This approach enables the quantification of disparities and the evaluation of the progress and improvements needed at local levels (13). The use of these strategies is becoming the norm, but in developing countries it requires improvements. Argentina is in an early stage. This work provides a precision public health tool to target public policies to those specific areas and populations with the greatest need, in order to increase the cost-effectiveness of the programs aimed to reduce undernutrition among children and reduce health disparities.

\section{Conclusions}

Overall, the prevalence of stunting in the most vulnerable child populations of Misiones province decreased significantly between 2009 and 2014, with differential improvement according to geographical location. The behaviour of the indicators is determined by the socioeconomic and environmental context at the health centre level. In this work we describe variables at the individual level that should be considered to reduce the prevalence of undernutrition. Also, we identify regional disparities and persistent spatial patches. This allows to map the peripheral urban and dispersed rural areas under vulnerable socioeconomic and environmental contexts that should be prioritized in health and nutrition public policies.

This article is protected by copyright. All rights reserved 


\section{Acknowledgments}

We gratefully acknowledge Oscar Herrera Ahuad and Edmundo Soria Vieta for their valuable comments on the article. The research was funded by the ANPCYT (FONCYT) and CONICET by PICT-2015-2353, PICTO2017-0094 to P.A.N and PIP 11220150100741CO, PICT-2017-1125 to M.R.R. The founders of this study had no role in study design, data collection, data analysis, data interpretation, or writing of the report. The corresponding author had final responsibility for the decision to submit for publication.

\section{References}

1. Black RE, Allen LH, Bhutta ZA, Caulfield LE, de Onis M, Ezzati M, et al. Maternal and child undernutrition: global and regional exposures and health consequences. Lancet. 2008;371(9608):24360.

2. Caulfield LE, de Onis M, Blossner M, Black RE. Undernutrition as an underlying cause of child deaths associated with diarrhea, pneumonia, malaria, and measles. Am J Clin Nutr. 2004;80(1):193-8.

3. Pelletier DL, Frongillo EA. Changes in child survival are strongly associated with changes in malnutrition in developing countries. J Nutr. 2003;133(1):107-19.

4. Bhutta ZA, Ahmed T, Black RE, Cousens S, Dewey K, Giugliani E, et al. What works? Interventions for maternal and child undernutrition and survival. Lancet. 2008;371(9610):417-40.

5. WHO. Physical status: the use and interpretation of anthropometry. Report of a WHO Expert Committee. World Health Organization Technical Report Series No 854. 1995:1-452.

6. Victora CG, Adair L, Fall C, Hallal PC, Martorell R, Richter L, et al. Maternal and child undernutrition: consequences for adult health and human capital. Lancet. 2008;371(9609):340-57.

7. Black RE, Victora CG, Walker SP, Bhutta ZA, Christian P, de Onis M, et al. Maternal and child undernutrition and overweight in low-income and middle-income countries. Lancet. 2013;382(9890):427-51.

8. Grantham-McGregor S, Cheung YB, Cueto S, Glewwe P, Richter L, Strupp B. Developmental potential in the first 5 years for children in developing countries. Lancet. 2007;369(9555):60-70.

9. Atun R, de Andrade LO, Almeida G, Cotlear D, Dmytraczenko T, Frenz P, et al. Health-system reform and universal health coverage in Latin America. Lancet. 2014.

10. Frenk J. Leading the way towards universal health coverage: a call to action. Lancet. 2015;385(9975):1352-8.

11. Nunez PA, Fernandez-Slezak D, Farall A, Szretter ME, Salomon OD, Valeggia CR. Impact of Universal Health Coverage on Child Growth and Nutrition in Argentina. Am J Public Health. 2016;106(4):720-6.

This article is protected by copyright. All rights reserved 
12. Adin A, Martinez-Bello DA, Lopez-Quilez A, Ugarte MD. Two-level resolution of relative risk of dengue disease in a hyperendemic city of Colombia. PLoS One. 2018;13(9):e0203382.

13. Osgood-Zimmerman A, Millear Al, Stubbs RW, Shields C, Pickering BV, Earl L, et al. Mapping child growth failure in Africa between 2000 and 2015. Nature. 2018;555(7694):41-7.

14. Reiner RC, Jr., Graetz N, Casey DC, Troeger C, Garcia GM, Mosser JF, et al. Variation in Childhood Diarrheal Morbidity and Mortality in Africa, 2000-2015. N Engl J Med. 2018;379(12):1128-38.

15. Bertonatti C, Corcuera J. Situación Ambiental Argentina 2000. Buenos Aires, Argentina: Fundación Vida Silvestre Argentina. 2000.

16. Cole TJ, Green PJ. Smoothing reference centile curves: the LMS method and penalized likelihood. Statistics in medicine. 1992;11(10):1305-19.

17. WHO. Child Growth Standards based on length/height, weight and age. WHO Multicentre Growth Reference Study Group. Acta Paediatr Suppl. 2006;450:76-85.

18. Okabe A, Boots BN, Sugihara K. Spatial Tessellations : Concepts and Applications of Voronoi Diagrams. Wiley Series in Probability and Mathematical Statistics ed1992.

19. INDEC. Censo Nacional de Población y Vivienda. Buenos Aires, Argentina: Instituto Nacional de Estadística y Censo de Argentina. 2010.

20. R Development Core Team. R: A language and environment for statistical computing. R Foundation for Statistical Computing. http://wwwR-projectorg/ 2019.

21. Blangiardo M, Cameletti M. Spatio-temporal models. In: Spatial and Spatiotemporal Bayesian Models with R-INLA. John Wiley \& Sons, Ltd. 2015.

22. Rue H, Martino S, Chopin N. Approximate Bayesian inference for latent Gaussian models by using integrated nested Laplace approximations. Journal of the Royal Statistical Society Series B (Statistical Methodology). 2009;71(2):319-92.

23. Knorr-Held L. Bayesian modelling of inseparable space-time variation in disease risk. Statistics in medicine. 2000;19(17-18):2555-67.

24. Wamani H, Astrom AN, Peterson S, Tumwine JK, Tylleskar T. Boys are more stunted than girls in subSaharan Africa: a meta-analysis of 16 demographic and health surveys. BMC Pediatr. 2007;7:17.

25. Cappa C, Wardlaw T, Morgan R. Disparities by sex in early childhood and adolescence. Lancet. 2011;378(9797):1122-3.

26. Kshatriya GK, Acharya SK. Gender Disparities in the Prevalence of Undernutrition and the Higher Risk among the Young Women of Indian Tribes. PLoS One. 2016;11(7):e0158308.

27. Alderman $\mathrm{H}$, Headey $\mathrm{D}$. The timing of growth faltering has important implications for observational analyses of the underlying determinants of nutrition outcomes. PLoS One. 2018;13(4):e0195904.

This article is protected by copyright. All rights reserved 
28. Lloyd SJ, Bangalore M, Chalabi Z, Kovats RS, Hallegatte S, Rozenberg J, et al. A Global-Level Model of the Potential Impacts of Climate Change on Child Stunting via Income and Food Price in 2030. Environ Health Perspect. 2018;126(9):97007.

29. Schmidt CW. The Future of Stunting: Potential Scenarios under Climate Change. Environ Health Perspect. 2019;127(4):44002.

30. Cooper MW, Brown ME, Hochrainer-Stigler S, Pflug G, McCallum I, Fritz S, et al. Mapping the effects of drought on child stunting. Proc Natl Acad Sci U S A. 2019;116(35):17219-24.

31. Rivero MR, De Angelo C, Nunez P, Salas M, Motta CE, Chiaretta A, et al. Environmental and sociodemographic individual, family and neighborhood factors associated with children intestinal parasitoses at Iguazu, in the subtropical northern border of Argentina. PLoS Negl Trop Dis. 2017;11(11):e0006098.

32. Rivero MR, De Angelo C, Nunez P, Salas M, Liang S. Intestinal parasitism and nutritional status among indigenous children from the Argentinian Atlantic Forest: Determinants of enteroparasites infections in minority populations. Acta Trop. 2018;187:248-56.

33. Hosseinpoor AR, Bergen N, Schlotheuber A, Boerma T. National health inequality monitoring: current challenges and opportunities. Glob Health Action. 2018;11(sup1):1392216.

34. Landmann-Szwarcwald C, Macinko J. A panorama of health inequalities in Brazil. Int J Equity Health. 2016;15(1):174.

35. Dowell S, Blazes D, Desmond-Hellmann S. Four steps to precision public health. Nature 2016;540:189-91

Correspondence: Pablo A. Nuñez, Grupo de Bioestadística Aplicada, Departamento de Ecología, Genética y Evolución, Instituto de Ecología, Genética y Evolución de Buenos Aires, Facultad de Ciencias Exactas y Naturales, Universidad de Buenos Aires, Intendente Güiraldes 2160, C1428EGA, Buenos Aires, Argentina. Email pb.nunez@gmail.com

This article is protected by copyright. All rights reserved 
A

B

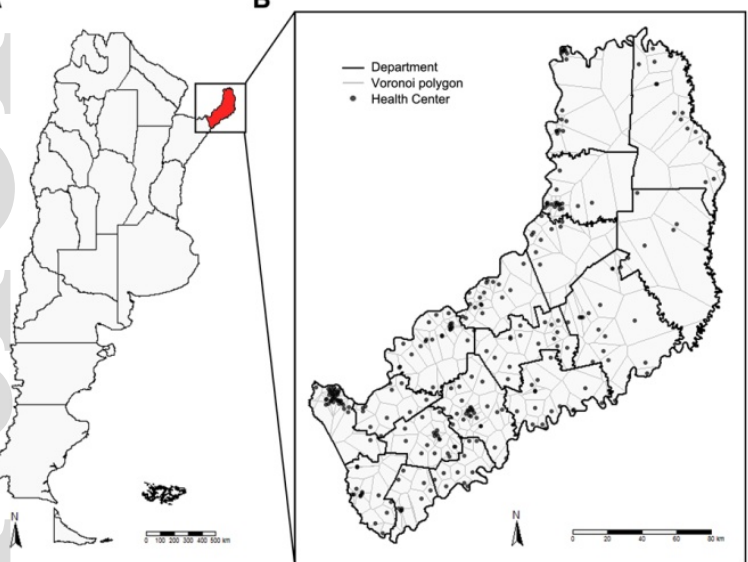

Figure 1. (A) Map of Argentina showing the Misiones province in red. (B) Map of Misiones province. The black line delimits the Department area. The grey line delimits the Voronoi Tessellation Area (VTA) which describes the influence area assigned to each health centre (PHCC) (black dot).

This article is protected by copyright. All rights reserved 
A

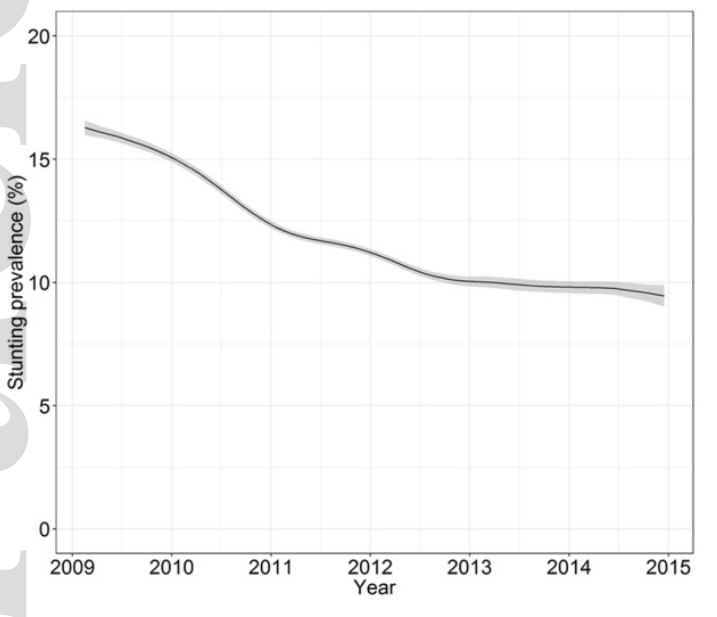

B

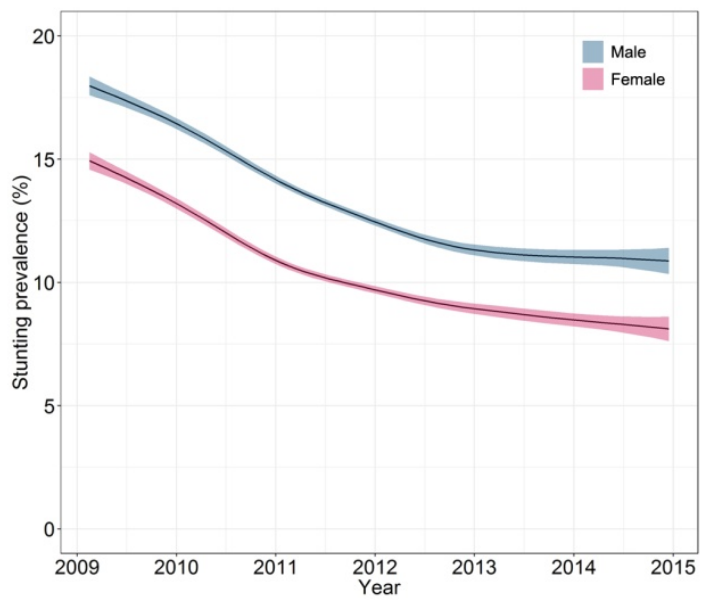

Figure 2. Trends in the prevalence of stunting by year in Misiones province (A) Estimated prevalence of stunting for the whole children population under 5 years of age. (B) Estimated prevalence of stunting for the whole children population under 5 years of age, by sex. 


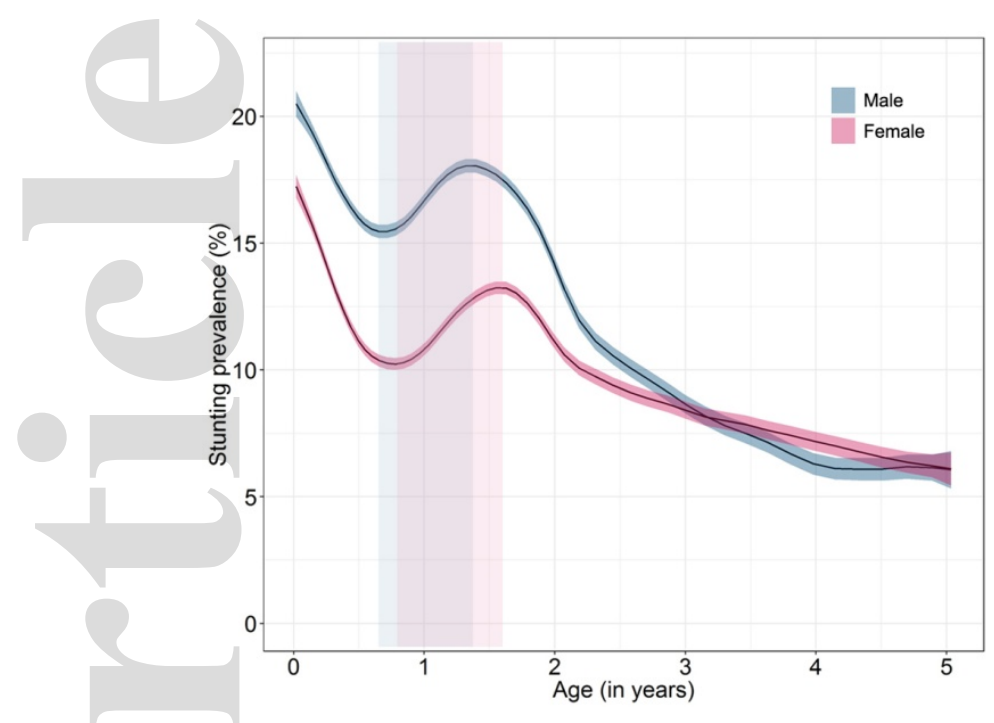

Figure 3. Estimated prevalence of stunting with age (in years) for the whole children population under 5 years of age, by sex.

This article is protected by copyright. All rights reserved 
A

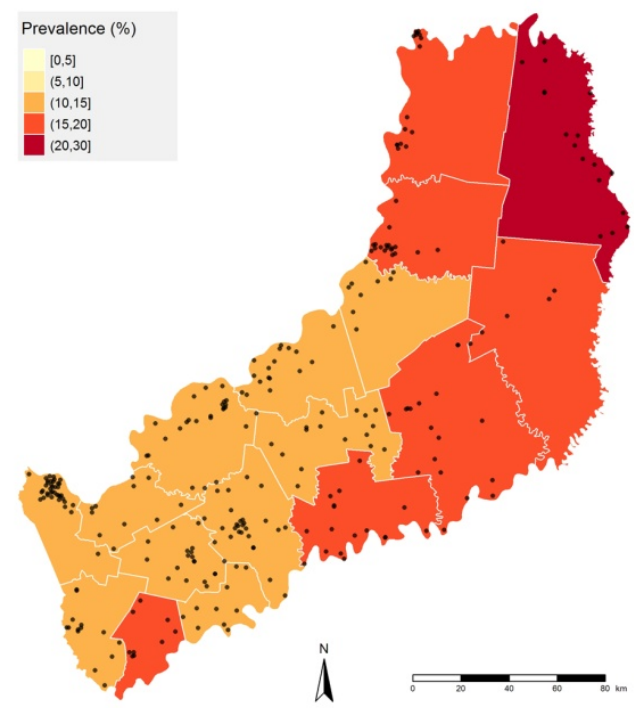

B

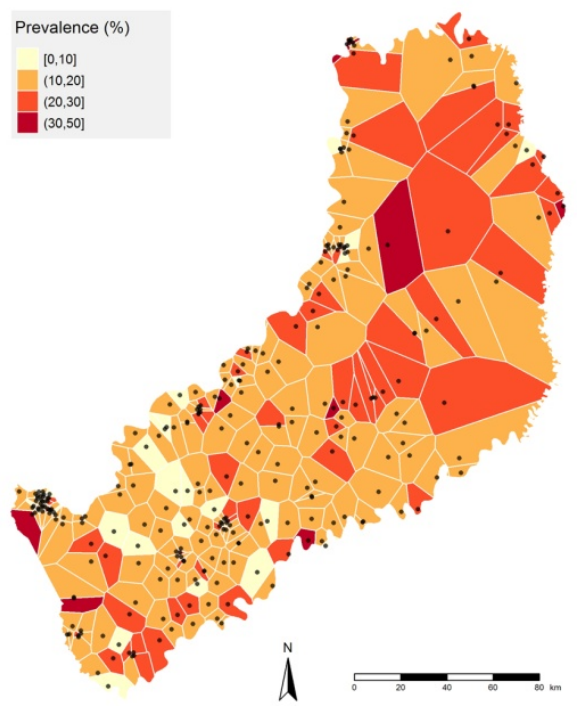

Figure 4. Map of Misiones province with the posterior mean estimates of spatial effects for the prevalence of stunting. (A) Department-level. (B) Health centre-level. 
A

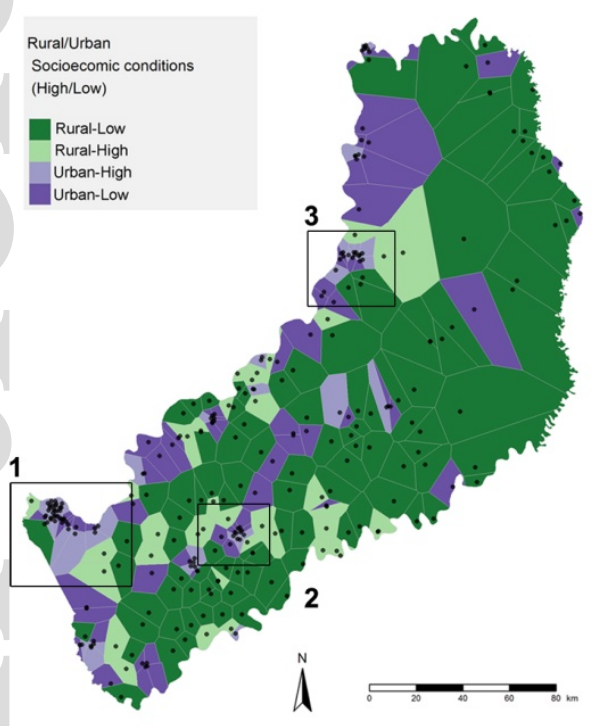

B

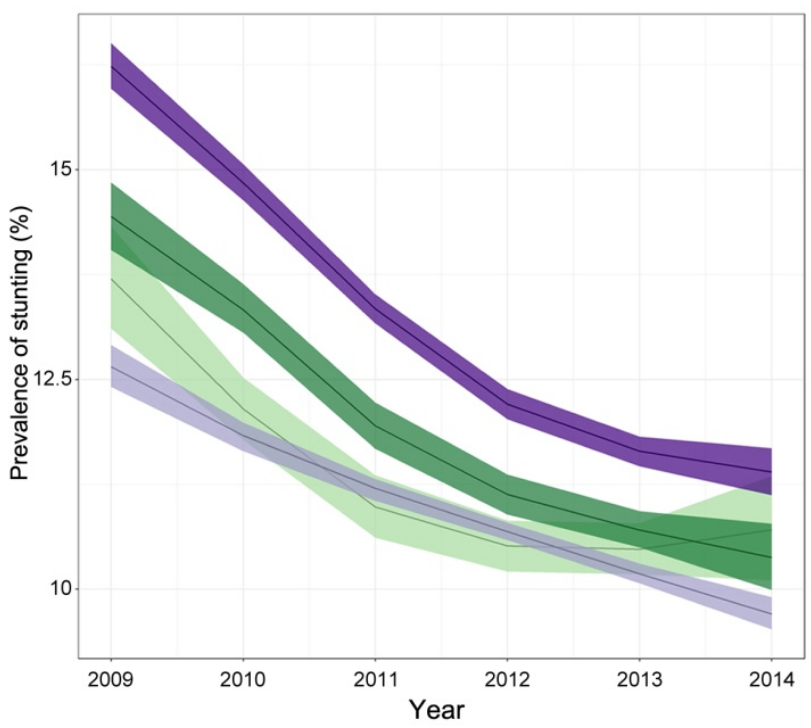

C

1

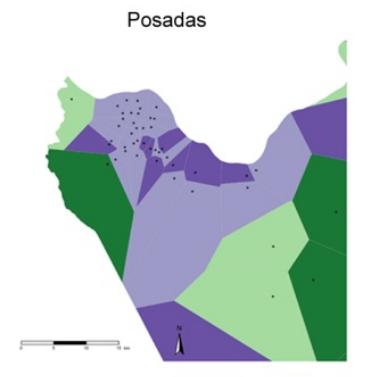

2

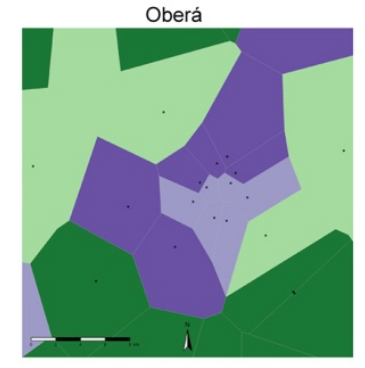

3

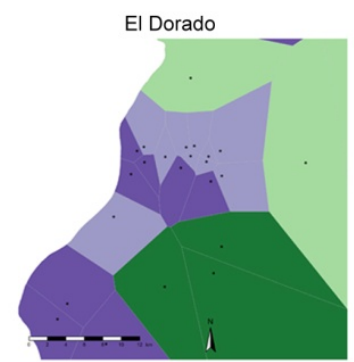

Figure 7. Spatial distribution and trends for the estimated prevalence of stunting by socioeconomic and environmental conditions clusters. (A) Maps of Misiones province with the distribution of the four clusters assigned to each PHCC determined by stratum (urban/rural) and socioeconomic conditions (highlow). (B) Estimate trends in the estimated prevalence of stunting by cluster. (C) Zoom in the three major cities: (1) Posadas, (2) Oberá and (3) El Dorado. 
Table 1. Porcentages of Public Health Care Centres (PHCC) that were assigned to one of the clusters according to their rural/urban context and their high/low socioeconomic level.

\begin{tabular}{|c|c|c|c|c|}
\hline \multirow[b]{3}{*}{ Socioeconomic variables ${ }^{2}$} & \multicolumn{4}{|l|}{ Clusters $^{1}$} \\
\hline & \multicolumn{2}{|l|}{ Rural } & \multicolumn{2}{|l|}{ Urban } \\
\hline & Rural-Low & Rural-High & Urban-Low & Urban-High \\
\hline $\begin{array}{l}\text { Households with unsatisfied basic } \\
\text { needs (UBN) }\end{array}$ & 24.2 & 18.4 & 22.0 & 12.6 \\
\hline Household with computer & 5.8 & 13.4 & 17.5 & 37.1 \\
\hline Household with phone & 1.4 & 8.0 & 15.2 & 38.2 \\
\hline Population using mobile phone & 68.5 & 78.2 & 80.8 & 87.1 \\
\hline Population using computer & 12.4 & 22.0 & 29.5 & 49.9 \\
\hline $\begin{array}{l}\text { Households living in an overcrowded } \\
\text { dwelling }\end{array}$ & 6.5 & 5.5 & 6.7 & 3.6 \\
\hline Own land for household & 62.3 & 65.3 & 68.5 & 67.0 \\
\hline Unemployment & 1.2 & 2.0 & 3.1 & 3.5 \\
\hline $\begin{array}{l}\text { Households with insufficient } \\
\text { construction quality }\end{array}$ & 75.9 & 54.4 & 48.7 & 21.0 \\
\hline $\begin{array}{l}\text { Households with insufficient public } \\
\text { services }\end{array}$ & 94.8 & 78.3 & 63,6 & 32.6 \\
\hline $\begin{array}{l}\text { Households with inadequate } \\
\text { construction materials }\end{array}$ & 28.6 & 14.1 & 17.0 & 5.9 \\
\hline Foreign inhabitants & 4.3 & 4.7 & 3.6 & 4.1 \\
\hline Population with $\geq 12$ years of education & 2.8 & 6.3 & 9.1 & 21.1 \\
\hline $\begin{array}{l}\text { Total percentage } \% \text { (number) of PHCC } \\
\text { assigned to each cluster }\end{array}$ & $37 \%(107)$ & $14 \%(39)$ & $25 \%(72)$ & $24 \%(70)$ \\
\hline $\begin{array}{l}\text { Total percentage } \% \text { (number) of PHCC } \\
\text { assigned to rural/urban clusters }\end{array}$ & $51 \%(146)$ & & $49 \%(142)$ & \\
\hline
\end{tabular}

${ }^{1}$ Each PHCC ( $\left.n=288\right)$ was assigned to one of the clusters according to their rural/urban context and their high/low socioeconomic level. Rural-Low: rural context and low socioeconomic level. Rural-High: rural 
context and high socioeconomic level. Urban-Low: urban context and low socioeconomic level. UrbanHigh: urban context and high socioeconomic level.

${ }^{2}$ Selected socioeconomic variables from last national census (19) used for PHCC assignment according to high or low socioeconomic level.

This article is protected by copyright. All rights reserved 